\title{
El sistema notarial argentino contemporáneo
}

\section{POR SEBASTIÁN JUSTO COSOLA $(*)$}

\begin{abstract}
Sumario: I. Introducción.- II. El notario.- III. Sistemas de acceso al notariado. Requisitos para acceder a la función notarial. Carácter vitalicio o no del ejercicio de la función pública notarial.- IV. Qué autoridad nombra al notario.- V. Organización interna del notariado.- VI. Existencia o no de un código ético o deontológico.- VII. Competencia del notario por razón de la materia y por razón del territorio.- VIII. Formación o no de protocolo notarial. Modalidades de protocolos según los distintos criterios clasificatorios que llevan los notarios. Existencia de protocolos para los documentos de más prolongada data.- IX. Tipología instrumental. Necesidad o no de concurrencia de los testigos a los instrumentos públicos.- X. Eficacia del instrumento público notarial. Criterios jurisprudenciales al respecto.- XI. Posibilidad o no de que puedan concurrir a los instrumentos públicos como comparecientes personas menores de edad y personas en situación de discapacidad.- XII. Aplicación por el notario local de las convenciones internacionales de derechos humanos.- XIII. Avances y retos para el notariado local en el orden tecnológico.- XIV. Bibliografía.
\end{abstract}

Resumen: el presente ensayo presenta un enfoque dinámico y ligero de las características generales del ejercicio de la función notarial en la República Argentina. El mismo se realiza sobre la base de los principios generales que el notariado de raigambre latina sostiene de manera clara y contundente.

Palabras claves: derecho notarial - notario - función notarial - deontología - protocolo

(*) Abogado y Escribano, Universidad Nacional de La Plata (UNLP). Dr. en Derecho, Universidad Austral. Esp. en Documentación y Contratación Notarial, Universidad Notarial Argentina. Posgraduado y especialista en Derecho de los Contratos y Daños, Universidad de Salamanca. Prof. Titular, Adjunto o Asociado (de grado y postgrado) de Derecho Notarial, Derechos de los contratos y ética de las profesiones jurídicas, Facultad de Derecho, Universidad de Buenos Aires (UBA); Facultad de Derecho, Universidad Nacional del Noroeste de la Provincia de Buenos Aires (UNNOBA); Universidad Notarial Argentina. Ex presidente del Consejo Consultivo de Ética del Consejo Federal del Notariado Argentino. Ex Becario del Consejo General del Notariado Español. Consejero superior titular por el claustro de docentes (UNNOBA). 


\section{The contemporary Argentine notarial system}

Abstract: this essay presents a dynamic and light approach to the general characteristics of the exercise of the notarial function in the Argentine Republic. It is carried out on the basis of the general principles that the notaries of Latin roots hold in a clear and forceful way.

Keywords: notarial law - notary - notarial function - deontology - protocol

\section{Introducción}

El origen de la función notarial responde a la necesidad social de efectuar una constatación de los hechos para que, sobre los mismos, se pueda configurar el elemento de la perpetuidad (Escobar de la Riva, 1957) en los documentos dotados de verdadera autenticidad y fuerza probatoria (Vallet de Goytisolo, 2004). Quienes ejercen la función notarial son dueños de una verdadera función autorizante instrumental (Otero y Valentín, 1933). La elaboración formal del documento notarial comienza a desarrollarse en la denominada Escuela de Bolonia (Pondé, 1967) sobre los aportes de los glosadores y post glosadores medievales, durante los primeros tiempos del siglo XII d.C (Núñez Lagos, 1964).

\section{El notario}

Lo antedicho se comprueba desde los estudios históricos acerca del documento que crea el escribano, el notario - o una persona con la misma función, pero designada de forma diversa o diferente-, siempre recordando que en cuestión de designación de quien oficia de fedatario, las cuestiones consuetudinarias regionales tienen una notable influencia (Diccionario del habla de los argentinos, 2008).

En la República Argentina, notario o escribano es la persona autorizada por el derecho a dar fe instrumental de los hechos actos y negocios jurídicos privados realizados de manera voluntaria (Gattari, 2008, p. 322). Es un operador del derecho, un jurista en ejercicio de una función pública y en todas las actividades que realiza, aun al momento de la constatación de un hecho material, ya que debe calificar el derecho a constatar como jurídico (Etchegaray-Capurro, 2011, p. 12). En general, se llama notario a quien se encuentra a cargo de un registro notarial habiendo accedido al mismo en cumplimiento de las prescripciones legales vigentes para la habilitación (Abella, 2010, p. 56). De acuerdo con su ejercicio de fe pública, se los clasifica en

a) Titulares, que son los que se encuentran a cargo de un registro notarial.

b) Adscriptos, que son los que, propuestos por el notario titular de un registro notarial, pueden actuar en ese registro cumpliendo determinados 
requisitos impuestos por las veintitrés demarcaciones provinciales y por la Ciudad Autónoma de Buenos Aires. El notario adscripto es una creación argentina, fundada en las necesidades del notario titular del registro de obtener "ayuda" para poder cumplir con el trabajo diario en la notaría. Tiene la misma competencia que el escribano titular de registro, quien, en el sistema de responsabilidad notarial, responde por él adscripto de forma solidaria. No es obligatorio contar con notarios adscriptos, aunque en general la figura se encuentra consolidada, y es más habitual que infrecuente encontrar en los registros notariales figuras de este tipo.

c) Suplente, que es el notario que actúa en un registro notarial frente a la ausencia temporaria del notario titular en uso de licencia. El notario que oficiará de suplente debe ser propuesto por el notario titular de registro.

d) Subrogante, es el notario que puede actuar en todo momento en el registro notarial de otro notario que también lo haya propuesto.

e) Interino, es el notario adscripto que actúa al frente del registro notarial ante su vacancia por renuncia, incapacidad o fallecimiento del notario titular hasta que el registro sea convocado a concurso (Abella, 2010, p. 58).

Uno de los temas centrales de la discusión notarial en Argentina fue, durante un tiempo prolongado, el tema de la naturaleza jurídica del notario: si era este o no era funcionario público. Inclusive la jurisprudencia de nuestro máximo tribunal ha reflejado, con distintas composiciones, distintas posturas: una de las más relevantes es la siguiente: "El escribano de registro es un profesional del derecho afectado a una actividad privada, pero con atributos que en parte lo equiparan a la gestión pública, cuyos actos, vinculados al comercio jurídico privado, dan fe de estas relaciones privadas y no expresan la voluntad del Estado como éste normalmente la exterioriza a través de sus órganos" (1).

Existen, también, otras referencias a la calidad de funcionario público de los fedatarios (2). De todos los aportes, la polémica más interesante del derecho notarial en torno a este tema fue la sostenida por la actual miembro de la Corte Suprema de Justicia de la Nación, Elena Highton (Highton de Nolasco, 1977; 2005) y por el recordado notarialista Eduardo Pondé (Pondé, 1977; 1994). Mientras que la primera se inclinaba a favor de la tesis del notario-funcionario con argumentos sustentados desde el derecho público, el segundo negaba categóricamente este carácter con argumentos provenientes del derecho privado notarial. Ambas

(1) CSJN, "Vadell, Jorge Fernando c/ Provincia de Buenos Aires". Fallos: 306:2030 (1984).

(2) CSJN: 13/08/1992. 
posturas, no obstante, se encuentran sólidamente argumentadas. La aparente conciliación académica llega a partir del aporte de Antonio Rodríguez Adrados en España, quien comprueba lo inútil de la discusión acerca de la naturaleza de la función, precisamente porque existen en ella dos componentes que se exhiben tan inherentes como inescindibles; el componente público, relacionado con la potestad fedante, y el componente privado, que se conforma en la tarea asesora, informativa, consultora e investigadora propia también de la función notarial (Rodríguez Adrados, 1996). Esa posición es la que en nuestro país sostiene categóricamente Cristina Noemí Armella (Armella, 1999).

Finalmente, queda por decir que se han efectuado discusiones menores en torno a las denominaciones de notario y escribano. Se suele argumentar que notario es quien tiene registro notarial, y escribano es aquel que tiene título universitario pero que carece de la investidura del Estado para actuar como notario, y por ello no cuenta con un registro notarial. Pienso que son expresiones académicas que no son oportunas y que, además, confunden al estudioso. En el ejemplo, el decreto-ley 9020/78, vigente en el ejercicio de la función en la provincia de Buenos Aires, establece que "a los efectos de esta ley solo es notario quien conforme a sus prescripciones se encuentre habilitado para actuar en un registro notarial de la Provincia" (artículo 1). Sin embargo, quienes ejercemos en esta demarcación nos encontramos colegiados dentro del Colegio de Escribanos de la Provincia de Buenos Aires. Es por ello que las denominaciones utilizadas tienen diferente impacto en las diferentes provincias del país y, especialmente, en la recepción sociológica de la función. Hay lugares donde la voz escribano es más frecuente, y otros, generalmente las grandes ciudades, en donde campea la voz notario.

Aunque etimológicamente las voces provengan de orígenes diferentes, son términos intercambiables en nuestro país.

\section{Sistemas de acceso al notariado. Requisitos para acceder a la función notarial. Carácter vitalicio o no del ejercicio de la función pública notarial}

Debe tenerse presente que la República Argentina es un país que tiene la forma de gobierno representativa, republicana y federal. En este sistema, las provincias se han reservado el poder de policía y, por ello, cada provincia tiene la potestad de regular el ejercicio de la función notarial de acuerdo con sus intereses. Lógicamente, las regulaciones son similares, aunque no coincidentes.

Consecuentemente, existen básicamente dos sistemas de acceso al ejercicio de la función notarial en la República Argentina. Ambos sistemas están reglados normativamente en cada provincia del país. 
Me refiero al denominado sistema de "acceso directo", a propuesta del titular del registro notarial para contar en el mismo con un escribano adscripto que sin concursar, puede acceder a la función notarial cumpliendo determinados requisitos - el caso, por ejemplo, de la Provincia de Buenos Aires (3), que además también tiene previsto el sistema de acceso por concurso (4) - y, por otro lado, el sistema notarial aludido de acceso por "concurso", generalmente establecido en todas las demarcaciones estaduales del país, donde cada postulante se somete rigurosamente a un concurso de oposición, mérito y antecedentes para poder obtener el registro notarial. En este último sistema, existen también demarcaciones que presentan ciertas particularidades propias, como el caso de la Ciudad Autónoma de Buenos Aires, donde el acceso al ejercicio de la función notarial siempre es a través de concurso, pudiendo el postulante obtener titularidad o adscripción a otro registro notarial ya existente (5). Debe tenerse presente que es el Poder Ejecutivo, o en todo caso, el Ministerio que corresponda, quien designa a los escribanos o notarios que acceden a la función por cualquiera de los sistemas aludidos.

Independientemente de cuál sea el sistema de acceso por demarcación, ambos regímenes presentan requisitos formales previos de acreditación referidos a las exigencias de ciudadanía, mayoría de edad, domicilio, título universitario expedido por Universidad pública o privada reconocida, y en especial, acreditación de certificado libre de antecedentes penales y buena conducta al matricularse. Este último requisito es esencial para el desarrollo del notariado del presente siglo, por cuanto posiciona a la ética como un baluarte indiscutido para el ejercicio de la función notarial (Armella, 1998, p. 355; Armella, 2013, p. 55).

Finalmente, la alusión a la competencia temporal del escribano. El ejercicio de la función fedante ocurre en un determinado periodo de duración del ejercicio de las facultades propias del escribano, notario, y de los funcionarios públicos en general. En este tema, al notariado nacional no le resulta ajeno lo resuelto por la Corte Suprema de Justicia de la Nación en el caso Franco (6), tan trascendente como relevante. En aquella memorable oportunidad, la Corte Nacional otorgó la razón a la escribana recurrente, priorizando por sobre todas las cosas el argumento que confirma que el solo hecho de alcanzar la edad de setenta y cinco años no revela la ausencia de condiciones para cumplir la función encomendada, y privar de la actividad a una persona que se encuentra digna y positivamente ejerciendo una

(3) Artículo 16, decreto ley 9020/1978 (T.O 1986).

(4) Artículo 7, decreto ley 9020/1978 (T.O 1986).

(5) Artículos 34 y 46, ley 404/2000.

(6) CSJN, 12/11/2002, "Franco, Blanca T. v. Provincia de Buenos Aires", JA 2003II464; Fallos 325:2968. 
función es contrario a las declaraciones, derechos y garantías que emanan de la Constitución Nacional.

En esta línea de pensamiento, debe también tenerse en cuenta que similares fueron los fundamentos vertidos oportunamente en el caso Fayt (Hernández, 2001). Similar situación ocurrió tiempo después en el Perú, aunque no llegó a la justicia por invocación de un interesado lesionado, sino que se elevó al mismo momento de la sanción y publicación del nuevo decreto legislativo de ejercicio del notariado (7).

No obstante lo referido, debe dejarse planteado en este desarrollo que, en los tiempos recientes, la Corte Suprema de Justicia de la Nación ha cambiado, por mayoría, el criterio sustentado en el referido caso Fayt, lo que hace suponer que lo resuelto en el caso Franco también podría correr la misma suerte. El fallo conocido públicamente como Schiffrin alterna el criterio ideológico sostenido desde los mencionados antecedentes hasta los días en que vivimos, sustentando nueva doctrina que confirma que los magistrados mayores de setenta y cinco años no pueden por principio, y salvo casos excepcionalísimos, continuar ejerciendo esa función(8).

\section{Qué autoridad nombra al notario}

La autoridad que designa al notario, tal como ya se ha referido, es el Poder Ejecutivo Estadual, para cualquiera de los sistemas de acceso a la función previstos en las normativas locales. En respeto a la autonomía estadual antes aludida, cada provincia puede delegar inclusive la designación en un órgano u organismo dependiente del poder ejecutivo. Pero es preciso aclarar que la autoridad habilita el registro notarial para funcionar siempre que se cumpla con las máximas y los principios del notariado latino, tal como el respeto al sistema cerrado o de numerus clausus notarial. Esto implica que cada vez que se llama a concurso se tienen en cuenta ciertas pautas para establecer la cantidad de registros notariales que se ofrecen, en razón de la cantidad de habitantes, el tráfico escriturario, etcétera. Consecuentemente, la apertura de registros notariales y la designación de escribanos o notarios al frente de los mismos responden a una investigación previa, generalmente informes que los propios colegios notariales efectúan a la autoridad de cuáles son las plazas a cubrir.

(7) “Colegios de Notarios de Puno, San Martín y Lima contra el decreto legislativo no 1049" Causa 00009-2009-PI/TC; 00015-2009-PI/TC; 00029-2009-PI/TC (acumulados) del 6/09/2010.

(8) CSJN 159/2012 (48-S), “Schiffrin, Leopoldo Héctor c/ Poder Ejecutivo Nacional s/ acción meramente declarativa", 28/03/2017. 
Una vez alcanzada la designación o habilitación, según sea el caso, la función del Colegio Notarial es la de tomar juramento, fecha desde la cual comienza a computarse el ejercicio temporal de la función notarial.

\section{Organización interna del notariado}

Producto de las inquietudes planteadas por los primeros congresos notariales argentinos (Primer Congreso Notarial Argentino, 1917), los colegios notariales fueron objeto de atención de la doctrina argentina transcurrida ya la segunda mitad del siglo pasado. Se han categorizado de diferentes maneras y se han proyectado sobre los mismos diferentes alcances (González, 1971; Fernández, 1998). Entre las funciones sobresalientes destaca las de asesoramiento a los colegiados y al público en general, inspección de protocolos, gobierno de la matrícula y disciplina del notariado.

Al referirse a la cuestión de la colegiación, no es posible dejar de hacer referencia a la figura que fuera José Adrián Negri. Para el recordado maestro del notariado argentino, era finalidad de los colegios notariales la de aspirar a la "mayor ilustración y respetabilidad del gremio" (Negri, 1966). De allí la idea de la creación del denominado "decálogo de la función los colegios profesionales", de referencia obligatoria en nuestro país, asegurando que un colegio notarial con amplias facultades de fiscalización haría alcanzar un alto grado de eficacia, pues esa vigilancia tendría ya el carácter de continuidad de que se carecía y las condiciones de dictabilidad indispensables para apreciar el grado de gravedad de cada infracción. De todas las condiciones que debían reunir los colegios notariales para alcanzar la excelencia, debe destacarse su preocupación por la cuestión deontológica en una referencia popular: "Una de las principales funciones del Colegio notarial es la de proyectar) la facultad y obligación de vigilancia y control permanente en el ejercicio profesional. La ética profesional ha de ser materia de una constante preocupación". Sobre sus ideas se construye el prestigio de la colegiación notarial en mi país.

El notariado argentino cuenta con un Colegio Notarial por demarcación territorial. Son veinticuatro Colegios notariales, incluida la Ciudad Autónoma de Buenos Aires, que tienen representación directa en el seno del Consejo Federal del Notariado Argentino. El Consejo Federal del Notariado Argentino, a su vez, forma parte de la Unión Internacional del Notariado, que es una institución mundial que nuclea actualmente a ochenta y nueve notariados del mundo.

En razón de las grandes extensiones de algunas de las provincias argentinas (9), y otras veces en el desarrollo habitacional de una ciudad en relación con la ciudad

(9) Es el caso de la provincia de Rio Negro. 
capital de la provincia - y en la necesidad de aplicar criterios político sociológicos diferentes-, algunos Colegios Notariales presentan sedes bien diferenciadas, siendo divididas las mismos por lo que se denomina "circunscripciones" (10). En este último caso, ambas circunscripciones tienen representación en el seno del Consejo Federal del Notariado Argentino.

Cabe decir que la organización interna del notariado argentino responde a los principios vigentes emergentes de la Unión Internacional del Notariado. Los principios de la función(11), los deontológicos(12) y los emergentes del Código de Ética respectivamente(13).

En el tema en estudio existe doctrina destacada en nuestro país que merece ser consultada a pesar del paso del tiempo (Bollini, 1985).

\section{Existencia o no de un código ético o deontológico}

En nuestro país la ética o deontología notarial presenta diversos modos de acceso y comprensión (Cosola, 2008; 2011). Asumiendo la triple declaración de principios de la Unión Internacional del Notariado antes aludido, cada provincia proyecta los deberes éticos notariales de acuerdo con lo que ordenan los estatutos fundacionales de cada colegio, los que con el paso del tiempo son actualizados - normativamente - o actualizables - a nivel argumentativo- en esta materia. Consecuentemente, cada provincia cuenta con reglas, códigos o normas relativas a la cuestión ética que son las que en general adopta el notariado de cada demarcación. Pero es relevante advertir que el Consejo Federal del Notariado Argentino cuenta en su seno, con un organismo esencial para el desarrollo de los deberes éticos notariales que se llama Consejo Consultivo de Ética, con funciones estatutarias relevantes en torno a la interpretación, argumentación, orientación y afirmación de los deberes éticos notariales en todo el país. Su creación obedeció oportunamente a la necesidad de contar con un organismo compuesto por pares que pueda ir haciendo doctrina deontológica frente a los casos patológicos que ocurren en el devenir del ejercicio profesional, especialmente frente a las demarcaciones donde no se cuenta con normativa existente, o con normativa confusa a nivel interpretativo. Su función más importante es la de emitir dictámenes no vinculantes que ayuden a las autoridades colegiales o a los órganos de disciplina notarial de cada territorio a interpretar si existe o no existe una falta de ética ante un caso de ausencia de norma o de dudosa aplicación por los derechos implicados en el mismo.

(10) Es el caso de la provincia de Santa Fe.

(11) Declaración de principios de la función notarial (Roma, 2005).

(12) Declaración de principios de deontología notarial (México, 2004).

(13) Deontología y Reglas de Organización del Notariado (Lima, 2013). 
Dichos dictámenes conformar una verdadera pieza de interpretación jurídica de los alcances éticos de la función notarial contemporánea en nuestro país, que son de acceso libre desde el sitio oficial del organismo. Recientemente, se le ha solicitado al organismo la misión de redactar las normas o principios deontológicos del notariado argentino, actividad que, por estos tiempos, se encuentra en vías de concreción.

\section{Competencia del notario por razón de la materia y por razón del territorio}

Al estudio del derecho, la voz competencia le resulta clara en ocasiones y muy confusa en otras situaciones. El recordado Lino Palacio advertía con verdadero acierto que la competencia es la medida de la jurisdicción (Palacio, 2014) y, con ello, aún más confuso se tornaba el estudio de estas instituciones.

El régimen de competencias en general, y notarial en especial, está determinado, entonces, por la ratione materiae, que ordena al notario obrar dentro de los límites de sus atribuciones (Armella, 1999). La competencia notarial en razón de la materia se encuentra, en principio, prevista en la ley. Sin embargo, por estos tiempos de constitucionalización del derecho privado, el notario puede también, ante casos específicos, recurrir a la denominada "elaboración notarial del derecho", que le permite crear el derecho documental a partir de los requerimientos especiales que sean necesarios para sostener, o salvaguardar un derecho esencial de la personalidad. Consecuentemente, el notario puede y debe conocer la interpretación constitucional y estar alerta ante la necesidad de tener que cumplir con todo requerimiento derecho ante cualquier situación que se le requiera. Las épocas de emergencia económica, sanitaria, financiera, educativa, y en especial los últimos tiempos del aislamiento social, preventivo y obligatorio impuesto por la pandemia generada por el virus COVID-19 es una prueba contundente de lo expresado. Elaborar notarialmente al derecho en el documento es, en cierta manera, sostener, como lo hicieron anteriormente los maestros José Castán Tobeñas (1946) y Juan Vallet de Goytisolo (2004), que es posible alcanzar un alto grado de justicia en los documentos notariales. Para "objetivizar" lo antedicho y que, por supuesto, no brinde lugar a malintencionadas interpretaciones, debe nada más que tenerse en cuenta que el Código Civil y Comercial de la Nación postula, en sus tres primeros artículos, que la fuente directa de interpretación y argumentación del derecho es la Constitución Nacional (artículo 1); que la interpretación de la ley debe ser teniendo en cuenta sus palabras, su finalidad, los derechos humanos que emergen de los tratados respectivos, los valores y principios del derecho, etcétera (artículo 2), y que las sentencias de los jueces deben ser razonables (artículo 3). Razonabilidad que, en el ejercicio del derecho notarial, por analogía, se traslada claramente al concepto de prudencia, por cuanto el objeto esencial de la función 
notarial es actuar en el marco del acuerdo, sin conflicto ni controversias, evitando con la documentación del mismo la generación de un conflicto posterior. En estos tres artículos mencionados se encuentra la clave del ejercicio notarial actual y, por ende, de sus consecuencias en la elaboración teórica y práctica de un documento. En consecuencia, la competencia material se encuentra establecida en la ley, lo que no obsta a que el notario pueda crear, en base a lo antedicho, un documento que sirva para sostener en el mismo, un derecho esencial.

En relación con la denominada competencia territorial, hay que decir que las atribuciones encomendadas al notario se deben ejercer en el espacio asignado por ley (14). El aludido principio de numerus clausus significa que cada ciudad tiene una cantidad determinada de escribanías en ejercicio, y por principio general, la actuación notarial de esos escribanos o escribanas no puede extenderse más allá de los límites el territorio asignado. Sin embargo, existen a nivel legislativo excepciones a este principio para casos puntuales, que permiten la extensión de la competencia notarial asignada (15). De esta manera, los instrumentos públicos notariales extendidos de acuerdo con lo que establece el orden jurídico vigente gozan de entera fe y producen idénticos efectos en todo el territorio de la República, cualquiera sea la jurisdicción donde se hayan otorgado(16). La Constitución Nacional establece que los actos públicos de una provincia gozan de entera fe en otra, y que es atribución del Congreso la determinación de la forma probatoria de esos actos (17) (Zarini, 1996). La manera de dotar de seguridad a la circulación de los documentos o instrumentos públicos es a través del sistema de legalizaciones(18). Fuera de ello, para que el documento surta efectos en el extranjero, requiere de la apostilla, si es que los efectos van a ocurrir en los países que adhieren a este sistema.

(14) "No existe ninguna disposición que impida otorgar la escritura pública traslativa del dominio en distinta jurisdicción de la del inmueble. Lo que la ley prohíbe es que se suscriba la escritura fuera del territorio que se ha asignado al escribano para el ejercicio de sus funciones, o sea, el desplazamiento de este a una jurisdicción ajena invadiendo la de otros". CNCiv., sala A, 22/11/1978, La Ley, 1979-A, 342.

(15) Artículo 130, decreto ley 9020/1978.

(16) Artículo 293 del CCiv. y Com.: "Competencia. Los instrumentos públicos extendidos de acuerdo con lo que establece este Código gozan de entera fe y producen idénticos efectos en todo el territorio de la República, cualquiera sea la jurisdicción donde se hayan otorgado".

(17) Artículo 7

(18) "La falta de legalización en la provincia de Córdoba del poder conferido en otra provincia del país, no obsta a su validez y eficacia, pues el artículo 980 del Código Civil -incorporado por la ley 24441- dispone que los instrumentos públicos extendidos de acuerdo a lo que establece el mismo código de fondo, gozan de entera fe y producen idénticos efectos en todo el territorio de la República Argentina, cualquiera sea la jurisdicción en que se hubiesen otorgado" CCiv. Com., Trab. y Flia. Villa Dolores, 18/08/2009, LLC 2010 (febrero) 115. 


\section{Concepto de protocolo. Modalidades de protocolos según los distintos criterios clasificatorios que llevan los notarios. La comprensión de su contenido: la publicidad cartular}

El protocolo es toda existencia reflejada en un documento que es advertida a través de una realidad con trascendencia jurídica (Lamber, 2003). El estudio del protocolo va unido a la historia de la documentación y, más precisamente, de la documentación notarial. El mismo ha mutado a través de los tiempos, y de ser una simple anotación conservada por el escribano sobre el documento redactado en pergamino, se erigió como documento original que el notario conserva ordenadamente (Lamber, 2003). En la República Argentina, como en el resto de los países del notariado romano germánico, el uso, cuidado y resguardo del protocolo se presenta como uno de los pilares de la función notarial (Lamber, 2003).

El estudio y elaboración del protocolo se aborda desde dos aspectos diferentes: uno de tipo particular, dirigido a conocer sobre las características y elementos externos configuradores del sustrato papel donde se redacta el documento notarial, y otro general, que se aprecia a la distancia, cuando el protocolo deja de ser un cuaderno compuesto por folios con numeración correlativa en el margen superior y logos que identifican al Colegio Notarial o institución emisora, para convertirse en los tomos anuales que con nota de apertura y de cierre, reúnen los documentos, la documentación incorporada, las notas marginales y el índice entre otros elementos de relevancia (Lamber, 2003). En sintonía con todo lo anteriormente expuesto, debe decirse que cada demarcación provincial cuenta con requisitos formales para la creación, elaboración, distribución, guarda y custodia del protocolo. Aunque diferentes entre sí, todas buscan alcanzar la máxima seguridad en su elaboración y distribución.

Pero en este tema es fundamental atender a los alcances de la denominada publicidad cartular. Cuente o no cuente la misma con recepción legislativa, lo cierto es que de la lectura del documento emergen dos vertientes de argumentación absolutamente relevantes. La primera de ellas, relacionada con la publicidad externa, y la segunda, con la publicidad interna.

Dentro de la teoría general, Rafael Núñez Lagos enseñaba que el mundo jurídico se divide en atención a la cuestión de las normas y la cuestión de los hechos, siendo únicamente relevantes los mencionados en último término si sirven de fuente para acreditar cualquier tipo de atribución de derechos subjetivos (Núñez Lagos, 2012). Es por ello que al derecho le importa que el hecho revele una existencia cierta, una persistencia o prueba, y una determinada valoración y eficacia. La correlación de cada una de estas fases hace producir la forma (Núñez Lagos, 2012). El hecho es jurídico a través de las formas, y las formas le imprimen al mismo el grado de eficacia (Núñez Lagos, 2012). A partir de la forma, la fuerza de la 
publicidad cartular externa -motivada desde el propio concepto de autenticidad externa-, se fundamenta desde situaciones absolutamente comprobadas por la doctrina notarial, que son las que confirman que la presunción de veracidad del documento, derivada de la expresión formal externa o exterior de un negocio jurídi$c o$, se capta y se recibe como válida tanto para lo probado como para lo expresado o declarado (Giménez-Arnau, 1964). La autenticidad externa, entonces, relacionada históricamente con la selladura o el sellado realizado por autoridad pública y otros signos o símbolos externos, imprime una seguridad cartular visible y palpable a ese hecho convertido en jurídico.

Por ello la publicidad cartular extrínseca no puede ser otra que la que se advierte, a simple vista, tanto de los textos matrices como de las primeras o ulteriores copias o testimonios y también, de los documentos anexos a las matrices:

a) Son documentos matrices aquellos producidos por la actividad fedante notarial directa e inmediata, que evidencia coetáneamente los hechos que ocurren en presencia del notario, que el mismo percibe por sus sentidos, procediendo a su narración (Pelosi, 1987) y luego a su guarda y custodia, hasta el momento oportuno - legal o consuetudinario- del depósito en el archivo que sea correspondiente. El principal de ellos es el denominado protocolo - cosa-, que una vez redactado queda en poder del notario, además de su guarda para que pueda sobre el mismo expedir copias (Etchegaray, 2016). Son documentos protocolares entonces las escrituras constitutivas, las de reconocimiento de relaciones jurídicas, las de "elevación a escritura pública de documento privado" y las de protocolización de instrumentos privados (Etchegaray, 2016).

b) Son copias o testimonios, independientemente del grado que detenten, aquellos que la doctrina considera como documentos reproducidos directos (desde los originales o matrices) e indirectos (desde una reproducción) (Etchegaray, 2016). La diferencia central entre las matrices y las copias o testimonios radica en la inmediación. Mientras que las matrices se realizan coetáneamente al hecho que se procede a autenticar, los testimonios y copias vienen a representar el hecho documento y no el hecho natural y humano que da origen al documento matriz, por ello es que se advierte de la conveniencia de llamarlos indistinta y genéricamente como reproducciones (Pelosi, 1965).

c) Finalmente, la referencia a otros documentos anexos hace alusión a aquellos que se agregan a las matrices, esencialmente al protocolo, de naturaleza administrativa, fiscal-tributaria o registral, de los que emergen también notas o rasgos relevantes de publicidad cartular. 
A este tipo de publicidad y a sus casos frecuentes se accede a través del estudio de títulos (Cosola, 2020).

Por el otro lado, se encuentran los efectos de la publicidad cartular interna. La historia del documento notarial es la historia de su lucha por la autenticidad inter$n a$ (Núñez Lagos, 2012). La misma, referida exclusivamente al contenido del documento y a su autenticidad en la esfera de los hechos, hace notar la existencia de tres grados de eficacia:

a) La verdad impuesta, compuesta de las narraciones que realiza y comete el notario captadas por sus sentidos, todas sus actuaciones y diligencias inter$n a$, determinantes de la fe pública como realidad evidente y como acto de fe interna (Núñez Lagos, 2012);

b) La verdad supuesta, compuesta por los hechos afirmados por el notario que no son evidencias indirectas, y las declaraciones de voluntad de las partes interna (Núñez Lagos, 2012), y

c) La verdad puesta, relacionada con el principio de prueba por escrito, son las declaraciones de verdad realizadas por las partes y las enunciativas internas (Núñez Lagos, 2012).

Es evidente que el tema de la autenticidad interna gira en torno a la cuestión de la fe, y dentro de ella al desarrollo de la fe pública. Desde mi visión, el tema debe exceder notablemente el análisis de ese valor, para extenderse hacia otros valores esenciales que, además, forman parte de la comprensión de la autenticidad a nivel interno. A la fe pública, analizada desde la certeza y desde los efectos del valor verdad, debe agregarse tanto el análisis de la justicia, referida al reflejo de la autonomía de la voluntad negocial vertida en el documento y tutelada notarialmente en el mismo momento de argumentación y creación documental, como la proyección de la seguridad jurídica, entendida como fuente de valoración de los efectos del documento que emana de la actuación notarial. La suma de los tres valores en el documento consolida la paz, que es el cuarto valor resultante de la adecuada concatenación de los tres anteriores mencionados, según demostraré en la parte tercera de esta investigación.

De esta forma, los análisis de los temas que componen la publicidad cartular intrínseca se relacionan exclusivamente con los aspectos valorativos y axiológicos contenidos y resguardados en el documento. Mientras que la publicidad cartular extrínseca tiene como misión el análisis de los efectos inmediatos de la publicidad (palpables y visibles), la publicidad cartular intrínseca persigue una cuestión diferente: analizar cómo es que se van o se han proyectado los valores en el documento; si los mismos se encuentran presentes o ausentes, si han sido adecuadamente 
ponderados por las partes y tutelados por el notario, y que efectos se desprenden de su adecuada implementación.

Para alcanzar a consolidar lo intrínseco de la publicidad en el documento, no es posible conformarse con un análisis meramente externo de los antecedentes, sino que aquí se desarrolla en plenitud la tarea predocumental notarial, relacionada con los deberes de información, el asesoramiento y el concejo notarial, de imparcialidad, independencia y aplicación y concreción del principio de legalidad integrada, que permiten alcanzar la adecuada comprensión de lo que realmente los comparecientes quieren realizar. No es el efecto regular de los negocios jurídicos, con la consecuente muestra de eficacia (inscripciones en término, prioridades, entre otros temas técnicos) lo que debe primar en este tipo de autenticidad, sino los efectos que compadecen la realidad, el deseo verdadero de las partes con el acto o negocio a instrumentar.

Este tema es quizás el más relevante a la hora de analizar el contenido del documento. En ocasiones cada vez más frecuentes se suele considerar a la instrumentación como una cuestión meramente técnica, que sí reúne todos los requisitos extrínsecos relativos a la forma se transforma en apta para consolidar el tráfico económico del mercado. El verdadero notario creador del derecho dirige su actividad hacia un fin mucho más amplio y relevante: adecuar la voluntad real de las partes que a él acuden en búsqueda de respuestas al derecho, procurando generar la plena satisfacción de cada una de ellas - y en lo que a cada cual le corresponda-, aunque esa actuación ni siquiera concluya en la creación misma del documento. Por ello, la autenticidad interna jamás podrá consolidarse en el documento ya realizado o finalizado, y por ello excede ampliamente la justificación de la autenticidad externa. La única posibilidad de concretar en un documento lo intrínseco es a través de la ponderación y de la tutela de cada valor comprometido antes de que los mismos sean definitivamente creados y, además, destinados a vivir, por el tiempo que sea, deseado o necesario, en un continente.

De todos los medios conocidos de publicidad que ofrece el derecho, el documento notarial es el único que puede lograr los valores proyectados instrumentalmente en el momento de la creación, los que, justificados, alcanzaran la máxima satisfacción de la voluntad jurídicamente tutelada (justicia), equivalente tanto a la certeza como a la verdad (fe), con la protección de la autenticidad externa aparente, que no es otra cosa que ver consolidada en él la libre y adecuada circulabilidad (seguridad).

A la publicidad cartular interna se accede inicialmente, analizando en el documento las cuestiones centrales de las manifestaciones notariales - aquellas cumplidas por el notario-, las propias de los comparecientes - aquellas que los mismos advierten en el documento-, y las relativas a los símbolos o signos exteriores, 
su orden y especialmente, el análisis del cumplimiento de cuestiones inherentes a un normal desarrollo del derecho documental (vigencia y cumplimiento de los plazos, solicitudes formales anexas al protocolo, la cuestión del otorgamiento y de la autorización, y demás cuestiones relacionadas). No hay diferencia, desde estas perspectivas, con el acceso a la autenticidad externa.

Sin embargo, de acuerdo con lo antes expuesto y desde el máximo nivel sustancial, el análisis de la publicidad cartular intrínseca cobra relevancia en el momento de creación del documento. Por ello el primer acercamiento corresponde a las partes o comparecientes que exponen sus deseos una vez acordada la voluntad, mientras que el acceso directo a la misma corresponde al notario que moldea esas intenciones, procediendo ubicarlas en el documento donde formalmente corresponde, protegiendo la voluntad y el derecho a través de la conformación real de los valores esenciales del documento. El elemento contenido se convierte hoy a lo que he referido como elaboración y creación notarial del derecho. Captadas las voluntades claramente expresadas, se crea y elabora el documento con la adecuada proyección de la autenticidad interna.

\section{Tipología instrumental. Necesidad o no de concurrencia de los testigos a los instrumentos públicos}

En nuestro país no son necesarios los testigos, salvo para casos legalmente previstos, como los dos testigos previstos en el Código Civil y Comercial de La Nación para la instrumentación del testamento por acto público (artículo 2479), que, inclusive, han quedado en la ley como rémora del derecho antiguo. Con la autorización notarial del documento que los comparecientes suscriben, se alcanzan los efectos probatorios, ejecutivos y conservatorios que la ley le asigna. Esto implica aceptar que la posición del testigo en los actos notariales es, principalmente, formal. Comprendido así el concepto de testigo como sujeto instrumental de indudable valor desde el aspecto formal del instrumento, el Código Civil y Comercial también prevé su presencia para casos especiales; entre otros, el del otorgante con discapacidad auditiva; en este caso, la intervención de dos testigos sirve para "dar cuenta del conocimiento y la comprensión del acto por parte de la persona autorizante" (artículo 304). Finalmente, debe decirse que existe en el aludido cuerpo legal una referencia a los testigos que resultan inhábiles para comparecer en el instrumento público, tales como las personas incapaces de ejercicio, o las que una sentencia les impuso la limitación de serlo; aquellas personas que no saben firmar, quienes sean dependientes del oficial público, como así también el cónyuge, conviviente y los parientes del mismo dentro del cuarto grado y segundo de afinidad (artículo 295). 


\section{Eficacia del instrumento público notarial}

El Código Civily Comercial de La Nación resguarda la consecuencia de la aplicación de la fe pública: el principio de autenticidad de los instrumentos públicos(19). El hombre no cree en los instrumentos o escrituras por nada más que porque así se le ordena creer: es el imperio de la fe pública, una creencia legalmente impuesta. De esta manera, la referencia a la autenticidad es, en definitiva, una remisión al valor probatorio del instrumento público, ya que el mismo goza indudablemente de la presunción de autenticidad que merece la actuación del oficial público interviniente, abonada por su firma y sello (Llambías, 1991). El instrumento público - a diferencia del particular y del privado- se prueba per se; se prueba a sí mismo. Una serie de signos exteriores fácilmente identificables - timbres, sellos, firma del autorizante- son presuntivamente suficientes para estar a lo que resulta del documento (Llambías, 1991). Si el documento notarial se exhibe como regular en cuanto a sus formas, el mismo se presume auténtico, y toda vez que la ley presume la autenticidad del instrumento considerado en sí mismo, releva a la parte que lo presenta de probar su autenticidad (Rivera, 2010).

En general, la doctrina llega a la convicción que el fundamento de la dación de fe no radica en la percepción del oficial, sino en las necesidades del tráfico jurídico que conlleva directamente al amparo de la seguridad jurídica (Orelle, 2001). Sin embargo y tal cual lo he dejado expuesto en el cuerpo de esta tesis, me permito insistir nuevamente en que, desde mi perspectiva, la sola referencia a la atribución legal no es en los tiempos actuales, enteramente suficiente. Definitivamente hace falta además otra tutela jurídica del derecho documental, que ocurre a partir de la creación de un elemento decisorio fidedigno que nace en manos de un profesional del derecho que cuenta con determinadas virtudes que desde un aspecto axiológico brinda mayor fuerza, vigor y certeza a los hechos que percibe y de los que da fe. La suma de los dos criterios exigidos para la dación de fe -los objetivos y los subjetivos- es lo que alcanza la excelencia en los efectos - y la eficacia generaldel documento notarial(20).

En el Código Civil y Comercial de La Nación, el instrumento público hace plena fe:

a) En cuanto a que se ha realizado el acto, la fecha, el lugar y los hechos que el oficial público enuncia como cumplidos por el o ante él hasta que sea declarado falso en juicio civil o criminal (artículo 296, inc. a).

(19) Artículo 296 del CCiv. y Com. El artículo guarda relación directa con el Código Civil de Vélez en los artículos 993, 994 y 995 respectivamente y notable similitud con el artículo 272 del Proyecto de Unificación de 1998, aunque con algunas diferencias en la redacción.

(20) Las virtudes del autor del documento se exigen objetivamente a través del pedido del acta de conducta al momento de ingresar a la función notarial. 
Hacen plena fe los instrumentos públicos de casos puntuales ya harto vistos y analizados por la doctrina mayoritaria: realización del acto, fecha y lugar. Por su parte, la enunciación de los hechos que el oficial público enuncia como por él cumplidos o que ante él han ocurrido o se han desarrollado, también hacen plena fe por cuanto es su propia investidura lo que permite que el valor probatorio sea verdaderamente fuerte y relevante (21). En derecho nacional se enseña que la propia naturaleza de la función fedante marca la necesidad de esta primera fase, y por eso con razón se afirma que la dación de fe requiere de un soporte factico, un objeto; se da fe de algo, ese algo es un hecho, y este debe ser percibido por el sujeto fedante (Carminio Castagno, 2006). Sobre esto, también se argumenta que se habla de la dación de fe perceptible por los cinco sentidos, y no solamente por los más comunes, que son la vista y el oído, por lo que no deben restringirse las percepciones sensoriales (Orelle, 2001). Estos actos, como así también en todos aquellos que reúnan los mencionados criterios, para ser negados, deben ser redargüidos de falso por acción civil o criminal:

b) En cuanto al contenido de las declaraciones sobre convenciones, disposiciones, pagos, reconocimientos y enunciaciones de hechos directamente relacionados con el objeto principal del acto instrumentado, hasta que se produzca prueba en contrario (artículo 296, inc. b).

En los instrumentos públicos deben distinguirse las declaraciones auténticas de las autenticadas(22). Las auténticas, que son las que emite el oficial, escribano, notario o funcionario público hacen plena fe hasta que sean redargüidas de falso, siempre recordando que temas elementales, como los juicios notariales de capacidad se encuentran excluidos lógicamente del alcance de la fe(23). Las otras declaraciones, denominadas comúnmente autenticadas, son aquellas que tienen valor en el instrumento, pero que no necesitan ser redargüidas de falsas, precisamente porque son las manifestadas por personas que no tienen el don indelega-

(21) Siempre que se expresa esto último, se hace especial referencia a la materialidad de los actos cumplidos en por él mismo o en presencia del oficial, y no de la sinceridad que a dichos acto corresponde.

(22) "Corresponde diferenciar la existencia material de los hechos que el escribano anuncia como cumplidos por él y sucedidos en su presencia, de las manifestaciones de las partes. Las declaraciones falsas por dolo, violencia, error, reserva mental o simulación, pueden conducir a la nulidad del negocio, pero no dan lugar al incidente de redargución de falsedad. El instrumento no puede declararse falso para las partes y verdadero para el escribano y compradores, por lo que la sentencia de falsedad hace cosa juzgada para todos" CNCiv., sala H, 14/07/2000, La Ley, 2000-E, 613.

(23) "Si lo que se cuestiona es el estado mental del poderdante y no su capacidad civil, no se está ante uno de los supuestos amparados por la buena fe, ya que la declaración de que el otorgante está en su perfecta razón, no es hecho comprobado por el oficial público". CNCiv., sala D, 14/11/1989, ED, 139-130. 
ble de la dación de fe. Las declaraciones de las partes acerca de las convenciones, disposiciones, pagos, reconocimientos y enunciaciones de hechos relacionados con el objeto principal del acto instrumentado, caerán por cualquier prueba en contrario. Objeto de la fe pública es el hecho perceptible del oficial de decir que ante el declararon, ante él se expresaron, ante él manifestaron. Pero la plena fe que emana del instrumento público no ampara la sinceridad de lo manifestado por los intervinientes en el instrumento.

Asimismo, por el principio de incolumidad formal, existe el impedimento legal para que el oficial público y los testigos no puedan contradecir las constancias obrantes en el documento (Llambías, 1991). En el Código Civil y Comercial de la Nación no está permitida la deposición del oficial o funcionario ni la de los testigos contra el instrumento (artículo 297 CCiv. y Com.), con el fin de resguardar la seguridad del instrumento legítimamente creado. La doctrina mayoritaria coincide con estas apreciaciones.

Finalmente, en nuestro país, la figura del contradocumento, como prueba del acto de simulación licita, es posible: se puede recurrir al mismo en determinadas circunstancias, para obtener de su aplicación un mejor resultado, tendiente a asegurar la voluntad y más que ello, la verdadera intención de las partes al realizar un acto, la bonificación y seguridad en la circulación de títulos, documentos o instrumentos varios. En efecto, la simulación no es reprobada por la ley cuando a nadie perjudica ni tiene un fin ilícito. En este sentido, el contradocumento opera como prueba de la simulación, entendiendo por tal la constancia escrita del verdadero carácter del acto simulado (Llambías, 1991). Si el principio es que la simulación licita a nadie afecta, puede tranquilamente admitirse en su faz documental que viene a alterar lo expresado en un instrumento público, ahora este principio tiene un límite impuesto más que por la ley, por el propio derecho: el daño a terceros interesados - los que verdaderamente tienen interés legítimo- de buena fe.

\section{Posibilidad o no de que puedan concurrir a los instrumentos públicos como comparecientes personas menores de edad y personas en situación de discapacidad}

Producto de la constitucionalización del derecho privado tal como la he referido anteriormente, no solo es posible sino también necesario la comparecencia de todo tipo de persona humana y su constancia en el documento notarial. Los nuevos vientos de interpretación jurídica y argumentación del derecho imponen a los juristas tener una visión constitucional del derecho a aplicar. No hay posibilidad que el notario desconozca este movimiento del derecho continental en todo su esplendor. El alcance de la intervención de las niñas, los niños y los adolescentes en el documento notarial, es uno de los grandes avances del derecho actual, 
que se aleja del sistema de control para pasar a garantizar el sistema de protección integral de los mismos (Armella y Cosola, 2011). La puesta en vigencia del Código Civil y Comercial de La Nación garantiza estos derechos normativamente (artículos 26, 645 y concordantes). El notariado bonaerense viene inclusive acompañado estas decisiones de normativización de principios esenciales referidos a la persona humana cualquiera fuera su franja etaria (Armella; Clusellas; Cosola; Moreyra; Salierno; Spina y Zito Fontán, 2019). En definitiva, existe un gran movimiento de estos derechos en nuestro país, al que lógicamente adscribo con total convencimiento.

El Código Civil y Comercial de la Nación es también un código que sostiene y resguarda la igualdad, de la misma manera que lo hacía, según vimos, el Código Civil Argentino de Vélez Sarsfield. Pero la referida igualdad, como baluarte del derecho contemporáneo, encuentra una proyección diferente, alejada totalmente del paradigma iluminista o decimonónico que la había cobijado en el pasado. La misma se aparta eficazmente de la consideración inflexible del derecho escrito, que ordenaba que los hombres y las mujeres, los niños, adolescentes y ancianos del pasado sean lo que podían ser en tanto centro de imputación de normas. La presente igualdad es una igualdad real, en desarrollo de una gran cantidad de normas que protegen la ética de los vulnerables, en un cuerpo codificado que presenta como paradigma esencial la no discriminación (Highton, 2015). Ya no es "el hombre" el sujeto por excelencia del derecho privado, como expresáramos al inicio del presente capítulo, sino también, a su lado, "la mujer, el niño, las personas con capacidades diferentes, el consumidor, las comunidades originarias, y muchos otros que no habían tenido una recepción sistemática hasta el momento" (Highton, 2015, p. 111). Una igualdad real que considera a la persona en el sentido de "ciudadano", sin distinciones etarias (Dabove, 2018), capaz de contemplar ambos aspectos del principio, el concreto y el abstracto (Lorenzetti, 2016). Esta concepción jurídica actual viene siendo desarrollada por la jurisprudencia de la Corte Suprema de Justicia de La Nación y la doctrina al menos, de los últimos treinta y cinco años, tal como lo hemos expuesto en los capítulos precedentes. Solo que ahora, esa fuerza y ese espíritu de la jurisprudencia y de la doctrina por alcanzar a llevar estos postulados al centro de atención del nuevo derecho, alcanzaron la normatividad.

El Código Civil y Comercial de La Nación prevé en artículos específicos la comparecencia de adolescentes para los casos en donde los mismos se encuentren involucrados. Así, al enumerar los casos en donde se requiere el consentimiento expreso de ambos progenitores en el ejercicio de la responsabilidad parental, se establece lo siguiente: "cuando el acto involucra a hijos adolescentes, es necesario su consentimiento expreso" (artículo 645). Lo que hace inferir que, en el ejemplo, una autorización notarial para que un adolescente pueda viajar al exterior requiere 
de su consentimiento, muy a pesar que el mismo pueda inclusive ser prestado en otras instituciones, como, por ejemplo, el departamento de migraciones.

En definitiva, esto explica, entre tantas otras cosas, que "la persona y sus derechos fundamentales sean la base que justifica el nuevo código" (Highton, 2015, p. 196), desde un criterio sustentado en una "fuerte tradición humanista" (Lorenzetti, 2016, p. 96).

\section{Aplicación por el notario local de las convenciones internacionales de derechos humanos}

Nuestro país se encuentra actualmente dentro el marco de la supremacía constitucional y convencional del derecho. Antes de la reforma constitucional del año 1994, existía el denominado Estado Constitucional del Derecho. Luego de ese año y hasta los tiempos presentes, sin vísperas de cambios en este tema, nos conformamos dentro del Estado Constitucional y Convencional del Derecho (Gil Domínguez, 2015, p. 29). Referirse a la constitucionalidad nos dirige a comprender las normas constitucionales, esencialmente en este tema, las emergentes de la parte dogmática, por ejemplo: la garantía de igualdad (artículo 16), incluidos los extranjeros (artículo 20); el derecho a la privacidad (artículo 19), y con ella, la reserva de papeles privados, la correspondencia e inviolabilidad del domicilio (artículo $18 \mathrm{in}$ fine); los derechos y garantías implícitas (artículo 33), etcétera.

Cuando nos referimos a la cuestión emergente de la convencionalidad, hacemos alusión a los instrumentos internacionales de Derechos Humanos que tienen jerarquía constitucional, los enumerados y los que sean aprobados por el Congreso de la Nación a través del mecanismo específico descripto al efecto (artículo 75 inciso 22) (Zarini, 1996; Quiroga Lavié, 2012). Por ejemplo, La Convención Americana de Derechos Humanos (Pacto de San José de Costa Rica), con vigencia legal en nuestro país como tratado (ley 23.054), y luego con rango constitucional (1994), deja leer en el preámbulo la necesidad de "consolidar un régimen de libertad personal y de justicia social fundado en el respeto de los derechos esenciales del hombre" que le son absolutamente correspondientes por la propia personalidad humana y no por el hecho de ser nacional de determinado Estado. Menciona a los derechos personalísimos: derecho a la vida (artículo 4); derecho a la integridad personal (artículo 5); derecho a la libertad personal (artículo 7), etcétera. Un tratado internacional que, a través de la enumeración de los derechos civiles y políticos, promueve la promoción de medidas legislativas a los Estados parte para garantizarla defensa de los derechos fundamentales (Redondo, 2020).

Los instrumentos internacionales no fueron incorporados a la Constitución Nacional. No forman para de ella. Comparten con la misma el ámbito normativo 
de supremacía (hay supremacía constitucional + convencional). Esto genera la existencia de dos fuentes de interpretación:

A) Una interna, que se alcanza a través de la lectura y comprensión de la Constitución;

B) Otra externa, que es la de la lectura de los Tratados de Derechos Humanos, con su propia lógica de funcionamiento.

Ambas fuentes son complementarias (artículo 75 inciso 22), quiere decir que se encuentran en plano de igualdad. Los Tratados de Derechos Humanos presentan jerarquía constitucional desde sus condiciones de vigencia estática: el momento en que el Estado Argentino los ratificó. Las condiciones de vigencia dinámicas, son las que surgen de las interpretaciones de los órganos que aplican estas normas. Las mismas pueden ser directas, cuando se refieren al Estado Argentino, o indirectas cuando se refieren a otros Estados.

Las dos fuentes también se "retroalimentan", "dialogan": en caso de colisión se aplica la alternativa más cercana a la persona.

El órgano encargado de interpretar la Constitución Nacional es la Corte Suprema de Justicia de la Nación, mientras que los encargados de interpretar los tratados son la Comisión Interamericana de Derechos Humanos y la Corte Interamericana de Derechos Humanos. Sin embargo, la Corte Suprema de Justicia Nacional no puede establecer cuál es la interpretación correcta de los tratados de derechos humanos, ni tampoco los órganos internacionales pueden obstaculizar la interpretación constitucional que efectué la Corte Suprema de Justicia de la Nación. Son dos fuentes jurídicas distintas, que comparten el mismo espacio, e irradian desde la supremacía a las relaciones de las personas con el estado y las personas entre sí (Gil Domínguez, 2015).

Consecuentemente, comprender la operatividad y aplicabilidad inmediata tanto del Pacto de San José de Costa Rica, como de las convenciones internacionales sobre derechos humanos ratificadas por Argentina, y de los tratados constitucionalizados es esencial, de la misma manera que la importancia del análisis de las decisiones tanto de la Comisión como de la Corte Interamericana de Derechos Humanos (Rivera, 2020). En definitiva, operatividad implica que todo tratado que reconozca en su cuerpo un derecho fundamental del hombre no requiere ninguna ley del Estado signatario para que el mismo pueda cumplirse y ejecutarse. Son los tribunales nacionales los que deben de aplicar el derecho internacional aludido. Su no aplicación genera una actuación institucional de la Comisión y Corte interamericana referida para restituir el goce de los derechos vulnerados y exigir al Estado infractor una indemnización (Barboza, 2017). 
Por lo demás, siempre es bueno recordar que la Constitución Alemana de Bonn es el instrumento que por primera vez ha aludido a la dignidad de la persona como concepto fundamental. Y también es el que ha dividido las aguas entre el concepto de ley y el concepto de derecho. Ley y derecho no son sinónimos, cuando se trata de analizar casos de injusticia extrema (Vigo, 2006). Precisamente es el Código Civil y Comercial de la Nación el que también divide o distingue, en su título preliminar, el derecho de la ley.

De aquí se deriva que, en el tema analizado, la aplicación práctica del notario no reconoce límite alguno, ya que, al redactar el documento, puede crear para integrarlo cuantas cláusulas crea conveniente para sostener que en el mismo se ha tenido en cuenta; en especial, el cumplimiento del derecho convencional. En este sentido, aunque el derecho se presume conocido, siempre es recomendable realizar una cita de los artículos o párrafos aludidos de las mencionadas convenciones.

\section{Avances y retos para el notariado local en el orden tecnológico}

La incorporación de las nociones tecnológicas al sistema jurídico actual y vigente, con sus normas, sus reglas y sus principios, si bien necesaria, debe ser prudente. Es necesario incorporar las herramientas tecnológicas de utilización diaria por el jurista compatibilizando sus efectos con las estructuras jurídicas vigentes: el acto jurídico, el contrato, las relaciones familiares, los derechos personalísimos, la conformación del título y el modo en los derechos reales, las cuestiones generales que permiten al menos inducir que en una determinada transacción puede existir blanqueo ilícito o desmedido de capitales, y por supuesto, con toda la cuestión constitucional relacionada con la protección de datos personales, el denominado derecho al olvido y toda aquella acción tecnológica compleja que esté relacionada, directa o indirectamente, a una determinada personalidad humana, entre otros casos relevantes.

¿Qué es la informática para el derecho? No es más que una herramienta al servicio de la personalidad humana. La misma se encuentra dirigida y destinada a aportar agilidad y celeridad a las transacciones, volviéndolas de alguna manera, mayormente posibles y probables entre más cantidad de personas que utilicen el mismo recurso.

Dentro del oficio del jurista, cada caso deberá ser analizado y canalizado de acuerdo con la incidencia que cada profesión tenga en la sociedad. En el caso estrictamente notarial, no puede ni debe descuidarse, de ninguna manera, la seguridad jurídica como valor esencial del derecho promovido por la fe pública. Las personas que recurren a la escribanía no dudan del trabajo notarial, porque la fe pública, más allá de las creencias personales, es una creencia que impone la ley. 
En el caso notarial, la protección de los derechos fundamentales en el seno del documento además de natural, es esencial.

Se trata entonces que la voluntad (real) de las partes, se ajuste al derecho (ley + normas + valores + principios) tutelados por un profesional del derecho en ejercicio de una función pública (certeza) que ordena y moldea su actuar ajustándolo a la voluntad de los requirentes (justicia). Si todas estas previsiones se cumplen, el resultado del documento creado y con el auxilio de la informática desde los alcances por nosotros establecidos, alcanzará la paz, que no es otra cosa que la previsión del conflicto (Cosola, 2013).

$\mathrm{Al}$ asumir que la informática es una herramienta que ayuda al derecho a concretar las necesidades de las personas, la misma debe encontrarse en sintonía con los derechos fundamentales reconocidos constitucionalmente, y no ser un medio que sea capaz de generar un daño a la propia personalidad. La manera de prevenir los daños o, en todo caso, de generar ante su acontecer la debida protección, es a través de una muy buena sistematización legislativa, en donde las leyes implicadas, de diferente naturaleza y alcance, se encuentren en armonía y en la búsqueda de los mismos fines. Quizás esto que afirmo no sea posible con leyes que describen un principio o un valor, las que necesariamente serán interpretadas con un criterio amplio y en ocasiones, también abstracto, pero si lo es con las leyes destinadas a reglar la informática, precisamente porque nos referimos a la cuestión formal, técnica, de procedimiento, que es el canal para el alcance de los derechos esenciales implicados en cada caso.

Desde la óptica notarial, la incorporación de las tecnologías de la información y la comunicación es posible siempre y cuando las mismas respeten el orden jurídico, con todo su alcance descripto anteriormente, siempre en procura de generar mayor certeza que incerteza desde su concreción formal. Con esto quiero expresar, por ejemplo, que, si el notario decide recurrir a una determinada criptomoneda para consolidar el precio en una compraventa, los recaudos a tomar en ese instrumento tienen que ser suficientes para que, ante lo imprevisto, pueda el mismo no perder su rumbo. Tal es así que el mismo deberá prever los modos de cumplimiento en especie diferente, que puede ser dinero de curso legal, o moneda extranjera, incluso la entrega de cosas de valor, por ejemplo, para poder reforzar la utilización de ese criptoactivo que hasta tanto no tenga una regulación legal, no presenta la seguridad jurídica propia de la contratación que el ejercicio de la función notarial debe tutelar.

En definitiva, no es posible en este tema perder de vista que detrás del perjuicio causado por la mala, imprudente o inoportuna utilización de las herramientas tecnológicas - muchas de las cuales en la actualidad se encuentran forzadamente a nuestra disposición- se posiciona la persona humana. Consecuentemente, 
rezagar un derecho es postergar a la propia persona (Serna y Toller, 2000). Ese es el lugar al que nunca debe llegar la función notarial.

\section{Bibliografía}

Abella, A. N. (2010). Derecho notarial. Buenos Aires: Zavalía.

Academia Argentina de Letras (2008). Diccionario del habla de los argentinos. Buenos Aires: La Nación.

Armella, C. N. (1998). Acceso a la función notarial. En Notariado Argentino, Buenos Aires: Consejo Federal del Notariado Argentino.

Armella, C. N. (1999). De los instrumentos públicos. En A. Bueres (Dir.), E. Highton (Coord.), Código Civil y normas complementarias. Análisis doctrinario y jurisprudencial, to 2C. Buenos Aires: Hammurabi.

Armella, C. N. y Cosola, S. J. (2011). Abordaje teórico-práctico del adelantamiento de la mayoría de edad. Ley 26.579. Buenos Aires: Ad-Hoc.

Armella, C. N. (2013). Acceso a la función notarial. En Instituto Guatemalteco de Derecho Notarial, Estudios de derecho notarial iberoamericano, Libro homenaje al profesor Dr. Nery Roberto Muñoz. Guatemala: Infoconsult Editores.

Armella, C. N.; Clusellas, E. G.; Cosola, S. J.; Moreyra, J. H.; Salierno, K. V.; Spina, Marcela V. y Zito Fontán, O. (2019). El notario. Ciencia, técnica y arte al servicio de las personas más vulnerables. La Plata: Colegio de Escribanos de la Provincia de Buenos Aires.

Barboza, J. (2017). Curso de organismos internacionales. Buenos Aires: Zavalía.

Bollini, J. A. (1985). Organización del notariado argentino. Buenos Aires: Edición del autor.

Carminio Castagno, J. C. (2006). Teoría general del acto notarial y otros estudios, to I. Paraná: Edición del autor.

Castán Tobeñas, J. (1946). Función notarial y elaboración notarial del derecho. Madrid: Reus.

Cosola, S. J. (2011). Ensayo para un esquema de presentación de los deberes éticos notariales. Buenos Aires: Consejo Federal del Notariado Argentino. 
Cosola, S. J. (2020). El documento notarial en el Código Civil y Comercial. Buenos Aires: Astrea.

Cosola, S. J. (2013). Fundamentos del derecho notarial, to I, La concreción del método. Buenos Aires: Ad-Hoc.

Cosola, S. J. (2008). Los deberes éticos notariales. Buenos Aires: Ad-Hoc.

Cosola, S. J. (2010). Los fundamentos éticos del derecho notarial. Lima: Arco Legal.

Dabove, M. I. (2018). Derecho de la vejez. Fundamentos y alcances. Buenos Aires: Astrea.

Escobar de la Riva, E. (1957). Tratado de derecho notarial. Valencia: Marfil.

Etchegaray, N. P. y Capurro, V. L. (2011). Derecho notarial aplicado. Buenos Aires: Astrea.

Etchegaray, N. P. (2016). Escrituras y actas notariales. Buenos Aires: Astrea.

Fernández Esteban, V. M. (1998). Los Colegios de Escribanos. Notariado Argentino. Buenos Aires: Consejo Federal del Notariado Argentino.

Gattari, C. N. (2008). Manual de derecho notarial. Buenos Aires: Abeledo Perrot.

Gil Domínguez, A. (2015). El estado constitucional y convencional de derecho en el Código Civil y Comercial. Buenos Aires: Ediar.

Giménez-Arnau, E. (1964). Derecho notarial español, vol. I. Pamplona: Universidad de Navarra.

González, C. E. (1971). Derecho notarial. Buenos Aires: Fedye.

Hernández, A. M. (h) (2001). El caso Fayt y sus implicancias constitucionales. Córdoba: Academia Nacional del Derecho y Ciencias Sociales de Córdoba - Advocatus.

Highton de Nolasco, E. I. (1977). Responsabilidad del estado por los escribanos por quien no es propietario. El caso de enajenación. $L L$ 1977-C (p. 954).

Highton, E. I. (dir.). (2005). La función notarial en la comunidad globalizada. Santa Fe: Rubinzal-Culzoni. 
Highton, E. I. (2016). La capacidad de los menores de edad. Revista de Derecho Privado y Comunitario. 2015-3, Santa Fe: Rubinzal-Culzoni.

Highton, E. I. (2015). Título preliminar del Código Civil y Comercial. Principios generales del derecho argentino. Revista de Derecho Privado y Comunitario, 2015-número extraordinario. Santa Fe: Rubinzal-Culzoni.

Lamber, R. A (2003). La escritura pública, tomo I. La Plata: FEN.

Llambías, J. J. (1991). Tratado de derecho civil-Parte General, tomo II. Buenos Aires: Editorial Perrot.

Lorenzetti, R. L (2016). Fundamentos de derecho privado. Código Civil y Comercial de la Nación Argentina. Buenos Aires: Thomson Reuters-La Ley.

Negri, J. A. (1966). Obras completas. Buenos Aires: Colegio de Escribanos de la Capital Federal.

Núñez Lagos, R. (2012). Documento público y autenticidad de fondo. En J. H. Alterini (dir.) y I. E. Alterini (coord.), Derecho Notarial, Registral e Inmobiliario. Doctrinas Magistrales 1897-2012, tomo I. Buenos Aires: La Ley.

Núñez Lagos, R. (1968). El documento Medieval y Rolandino. La Plata: Universidad Notarial Argentina.

Orelle, J. M. R. (2001). De los instrumentos públicos. En A. Belluscio (dir.) y E. A. Zannoni (Coord.), Código civil y leyes complementarias. Comentado, anotado y concordado. Tomo 4. Buenos Aires: Astrea.

Otero y Valentín, J. (1933). Sistema de la función notarial. Barcelona: Artes Gráficas.

Palacio, L. E. (2014). Manual de derecho procesal civil. Buenos Aires: La Ley.

Pelosi, C. A. (1965). Colegiación obligatoria: su relación con el decoro del cuerpo notarial y los principios de ética profesional. La Plata: Colegio de Escribanos de la Provincia de Buenos Aires.

Pelosi, C. A. (1965). Estudios jurídicos notariales. Buenos Aires: Abeledo Perrot.

Pondé, E. B. (1994). La función notarial no es función pública. Revista Notarial, número 917. La Plata: Colegio de Escribanos de la Provincia de Buenos Aires.

Pondé, E. B. (1967). Origen e historia del notariado. Buenos Aires: Depalma. 
Pondé, E. B. (1977). Tríptico Notarial. Buenos Aires: Depalma. Aires.

Primer Congreso Notarial Argentino, Actas y antecedentes (1917). Buenos

Primer congreso notarial argentino (1967). La Plata: Colegio de Escribanos de la Provincia de Buenos Aires.

Quiroga Lavié, H. (2012). Constitución de la Nación Argentina comentada. Buenos Aires: Zavalía.

Redondo, M. B. (2020). Tratados internacionales de derechos humanos comentados. Rosario: Juris.

Rivera, J. C. (2010). Instituciones de derecho civil. Parte General, tomo II. Buenos Aires: Abeledo Perrot.

Rivera, J. C. (2020). Instituciones de derecho civil. Parte General, tomo I. Buenos Aires: Abeledo Perrot.

Rodríguez Adrados, A. (1996). El notario: función privada y función pública: su inescindibilidad. Escritos Jurídicos, tomo II. Madrid: Consejo General del Notariado Español.

Serna, P. y Toller, F. (2000). La interpretación constitucional de los derechos fundamentales. Buenos Aires: La Ley.

Vallet de Goytisolo, J. B. (2004). Manuales de metodología jurídica, tomo III. Madrid: Consejo General del Notariado.

Vigo, R. L. (2006). La injusticia extrema no es derecho (de Radbruch a Alexy). Buenos Aires: Departamento de Publicaciones, Facultad de Derecho (UBA) - La Ley.

Zarini, H. J. (1996). Constitución Argentina. Comentada y concordada. Buenos Aires: Astrea.

Fecha de recepción: 30-03-2021

Fecha de aceptación: 23-08-2021 
